\title{
Future water quality monitoring: improving the balance between exposure and toxicity assessments of real-world pollutant mixtures
}

Rolf Altenburger ${ }^{1,2^{*}} \mathbb{0}$, Werner Brack ${ }^{1,2}$, Robert M. Burgess ${ }^{3}$, Wibke Busch ${ }^{1}$, Beate I. Escher ${ }^{1,4}$, Andreas Focks ${ }^{5}$, L. Mark Hewitt ${ }^{6}$, Bo N. Jacobsen ${ }^{7}$, Miren López de Alda ${ }^{8}$, Selim Ait-Aissa ${ }^{9}$, Thomas Backhaus ${ }^{10}$, Antoni Ginebreda ${ }^{8}$, Klára Hilscherová ${ }^{11}$, Juliane Hollender ${ }^{12}$, Henner Hollert ${ }^{2}$, Peta A. Neale ${ }^{13}$, Tobias Schulze ${ }^{1}$, Emma L. Schymanski ${ }^{12,14}$, Ivana Teodorovic ${ }^{15}$, Andrew J. Tindall ${ }^{16}$, Gisela de Aragão Umbuzeiro ${ }^{17}$, Branislav Vrana ${ }^{11}$, Bozo Zonja ${ }^{8}$ and Martin Krauss ${ }^{1}$

\begin{abstract}
Environmental water quality monitoring aims to provide the data required for safeguarding the environment against adverse biological effects from multiple chemical contamination arising from anthropogenic diffuse emissions and point sources. Here, we integrate the experience of the international EU-funded project SOLUTIONS to shift the focus of water monitoring from a few legacy chemicals to complex chemical mixtures, and to identify relevant drivers of toxic effects. Monitoring serves a range of purposes, from control of chemical and ecological status compliance to safeguarding specific water uses, such as drinking water abstraction. Various water sampling techniques, chemical target, suspect and non-target analyses as well as an array of in vitro, in vivo and in situ bioanalytical methods were advanced to improve monitoring of water contamination. Major improvements for broader applicability include tailored sampling techniques, screening and identification techniques for a broader and more diverse set of chemicals, higher detection sensitivity, standardized protocols for chemical, toxicological, and ecological assessments combined with systematic evidence evaluation techniques. No single method or combination of methods is able to meet all divergent monitoring purposes. Current monitoring approaches tend to emphasize either targeted exposure or effect detection. Here, we argue that, irrespective of the specific purpose, assessment of monitoring results would benefit substantially from obtaining and linking information on the occurrence of both chemicals and potentially adverse biological effects. In this paper, we specify the information required to: (1) identify relevant contaminants, (2) assess the impact of contamination in aquatic ecosystems, or (3) quantify cause-effect relationships between contaminants and adverse effects. Specific strategies to link chemical and bioanalytical information are outlined for each of these distinct goals. These strategies have been developed and explored using case studies in the Danube and Rhine river basins as well as for rivers of the Iberian Peninsula. Current water quality assessment suffers from biases resulting from differences in approaches and associated uncertainty analyses. While exposure approaches tend to ignore data gaps (i.e., missing contaminants), effect-based approaches penalize data gaps with increased uncertainty factors. This integrated work suggests systematic ways to deal with mixture exposures and combined effects in a more balanced way, and thus provides guidance for future tailored environmental monitoring.
\end{abstract}

Keywords: Water monitoring, Mixture toxicity, Water framework directive, Bioanalysis, Ecological assessment, Chemical and ecological status

\footnotetext{
*Correspondence: rolf.altenburger@ufz.de

1 UFZ-Helmholtz Centre for Environmental Research, Permoserstr. 15, 04318 Leipzig, Germany

Full list of author information is available at the end of the article
} 


\section{Introduction}

The Water Framework Directive (WFD) [29] is a visionary piece of environmental legislation that strives to achieve a good water status in Europe [4]. However, the first and second rounds of European water monitoring efforts have shown that European water bodies fail to achieve a good status to a large extent [20,22]. In this case, the WFD foresees that: 'Member States shall use the information collected above, and any other relevant information including existing environmental monitoring data, to carry out an assessment of the likelihood that surface waters bodies within the river basin district will fail to meet the environmental quality objectives set for the bodies ... [29]. The WFD is due for review in 2019. To meet its goals, there seems to be a widespread consensus that effort towards monitoring and assessing the chemical and ecological status should be readjusted into a more coherent approach to achieve a better quality of European freshwaters [11].

Issues to be addressed in future water monitoring include more systematic efforts to identify contaminants relevant for compromised water qualities, as well as improved quantification of compounds that are of high biological activity. To improve detection of bioactive compounds, sampling strategies tailored for specific exposure situations, effect-based detection, and protection goals are required. Also, accommodating for the occurrence of mixtures of contaminants and combined effects requires revision of assessment perspectives that focus on single compounds [1]. Further needs include options for indication of site-specific biological effects and sources of contamination, evaluation of management measures, and allocation of the magnitude of different stressors accounting for the dynamics of changes in stressor impact.

Methodological progress has been made in many fields relevant for monitoring approaches, such as contaminant screening based on high-resolution mass spectrometry, effect monitoring using transfected receptor bioassays and open access data repositories. Clearly, however, it is not sufficient to rely on individual technical inventions to meet the challenges outlined above. Malaj et al. [41] using EU water monitoring data as well as Moschet et al. [42] exploring multi-compound detection in a case study demonstrated that the assessed environmental risk increases with the number of chemicals being analyzed in water bodies. This finding is the result of how we deal with missing values when assessing monitoring data. In risk assessment, detected concentrations of preselected chemical(s) are compared with their environmental quality standard (EQS). EQS are derived using worst case assumptions and the concept of an overall threshold. The predicted no-effect concentration (PNEC) across all protected receptors becomes central for the EQS derivation [30]. Thus, while on the chemical exposure side, missing detections are generally ignored (i.e., the less we know about chemical occurrence in surface waters, the better the result in status assessment), on the effect assessment side, knowledge gaps are penalized with uncertainty factors. The latter approach of dealing with uncertainty is adopted from prospective chemical risk assessment. Here, the less we know about the adverse effects of a contaminant, the more caution (i.e., higher safety factors) we use to derive assessment values. Our current assessment may, thus, be severely confounded due to a bias in data generation, where only a few preselected chemicals are monitored and assessed against laboratory-based toxicity information. Furthermore, the highly complex structural biological parameters used to assess an ecological status are monitored independently and are not considered in relation to contaminant exposure. In this setting, it remains difficult to identify contamination as a causative factor for an insufficient ecological status or to identify sources or drivers of adverse effects.

To better link the information already available with reasonable additional efforts in the context of chemical contamination and ecological status assessments, we aimed to develop more balanced approaches for exposure and effect monitoring of freshwater quality. As laid out in Altenburger et al. [1], we think it is essential for future water monitoring to account for chemical mixture occurrence and effects. Moreover, we suggested developing distinct solution-oriented monitoring strategies. The three strategies developed here are designed to (1) identify compounds of concern for specific river basins, (2) assess ecological impact of contamination across different sites, and (3) establish causal relationships between chemical contamination and biological effects. Each of the strategies builds on specific combinations of information from chemical and biological analyses, with a primary focus on organic contaminants. We build on the experience of 5 years of research in the EU-funded SOLUTIONS project (http://www. solutions-project.eu/) with regard to the development of experimental and observational tools [1] and their application in various case studies [8]. The suggestions laid out here document a synthesis of many different ideas and studies. We, thus, intend to provide guidance for policy makers and water resource managers, demonstrating improved strategies to deal with mixtures of pollutants in water resource management. 


\section{Identification of river basin-specific pollutants}

Within the WFD context, members are obliged not only to monitor certain agreed contaminants across all EU member states (so-called priority substances) but also to identify pollutants of regional or local importance and monitor these eventually as river basin-specific pollutants (RBSPs) [53]. The current means of identifying RBSPs is typically to list candidate substances from existing legislation and select certain substances using monitoring information and/or modeling-based priority setting schemes [53]. These procedures depend on the availability of suitable data both on the exposure and effect side, which often remains fragmentary. Significant progress in dealing with data gaps has been achieved through an initiative of the NORMAN association [19] which suggests a framework to cope with uncertainty, and thus assists the consideration of compounds with incomplete data sets [67]. Nonetheless, the identification of RBSPs depends on the availability of suitable chemical analytical methodologies, which are able to demonstrate the occurrence of contaminants at biologically relevant concentrations, i.e., concentrations around the PNECs of the individual compounds.

Development of improved, cost-efficient methodologies is key to overcome these current limitations. In SOLUTIONS, we focused on passive sampling methods that provide estimates of time-weighted average freely dissolved concentrations of trace organic compounds, and high-volume sampling techniques that provide simultaneous access to chemical and bioanalytical analysis, and development of multi-residue methods of higher sensitivity. These sampling techniques provide improved exposure estimates that can subsequently be used in conjunction with available effect information for biological quality elements (BQEs: fish, macroinvertebrates, phytoplankton, macrophytes) to identify the specific toxicological relevance of contaminants.

\section{Passive sampling}

Using passive sampling methods to identify RBSPs during (chemical) monitoring offers several advantages for biological exposure characterization. Firstly, passive sampling can provide time-integrated information about specific aquatic pollutants over extended time periods (several weeks-months). This is a more realistic reflection of aquatic organism exposure in surface waters, compared to grab sample analysis (unless monitoring a discrete pollution event, where grab sampling may be more suitable). Secondly, passive samplers provide a measure of freely dissolved concentrations, rather than total concentrations. Freely dissolved concentrations are thought to be more comparable with singlechemical effect concentrations for aquatic species from laboratory studies (used in risk assessment for aquatic environments), due to their proportionality to the chemical potential and chemical activity [54]. Finally, passive sampler concentrations, after equilibration with sampled media, allow for a direct comparison of chemical levels in various compartments, thus helping to assess the compartmental distribution and to consider source and sink relationships, as well as to study accumulation and magnification of chemicals in aquatic biota. A guidance document on the use of passive sampling methods, resulting from the various efforts in SOLUTIONS, is provided [69].

A novel mobile dynamic passive sampling approach was introduced, which is applicable for characterizing chemical pollution along large rivers, lakes or sea transects, providing samples with chemical patterns integrated in time and space. This approach was applied in the Joint Danube Survey JDS3 [52, 68]. A case study on the combination of passive sampling, multi-residue analysis, and bioassays demonstrated the occurrence of 107 (out of 168) priority and emerging pollutants in the river Bosna (Bosnia and Herzegovina) [65]. The city of Sarajevo was identified as a major source of pollution, with downstream samples showing significant responses in all bioassays. While the estrogenic activity was largely explained by the specific estrogens measured, the drivers of the other observed effects remain largely unknown. Various compounds (diazinon, diclofenac, $17 \beta$-estradiol, estrone, benzo[k]fluoranthene, fluoranthene and benzo[k]fluoranthene) exhibited potential risks to aquatic biota, and indicated an inadequate water treatment infrastructure [65].

\section{In situ large-volume solid-phase extraction}

Combining chemical and bioanalytical techniques to characterize water samples shows great potential for identifying pollutants of potential concern more coherently, as component-based effect assessment can be compared with effect observations in the same sample [55]. Current limitations mostly relate to the amount of sample required for biological analysis, which typically involves multiple bioassays and enriched samples [1]. To overcome the logistical challenges associated with providing access to hundreds of liters of water samples, a novel, automated-solid phase extraction (LV-SPE) device was developed and tested for organic compound recoveries [60]. Good recoveries were observed for more than 200 compounds exhibiting a wide range of physicochemical properties. Moreover, the generated extracts proved suitable for biotesting using various in vitro and in vivo bioassays [50], with effect recovery observations similar to those for chemical recovery for LV-SPE [51]. The device was used in various case studies comparing 
chemical and bioanalytical findings, to study how much of an observable effect in freshwater might be explained through chemical analysis using a bioanalytical equivalent concentration (BEQ) approach (e.g., [38, 47, 64].

\section{Chemical analytical methods}

The identification of RBSPs is desirable for chemical monitoring. Analytical methods to detect contaminants in low concentrations in water have improved progressively over time. A review of water contaminant detection performed at the onset of the SOLUTIONS project demonstrated that over 400 organic compounds were detected in European freshwaters, but that the overlap in the compounds analyzed was low due to the different multi-compound methods used [15]. Only 13 of the 426 compounds found were analyzed in all of the seven studies reviewed. Thus, it is currently difficult to tell whether reports on specific compound detections are site or method specific (or both). To improve transparency and allow for more rational choice and comparison of methods, we compiled standard operating procedures (SOPs) for more than 250 water contaminants. These SOPs were in two main forms. Firstly, 'Master Methods' contained detailed information on the multi-residue approaches developed to analyze different classes of priority and emerging pollutants (e.g., polycyclic aromatic hydrocarbons, polychlorinated biphenyls, organochlorine pesticides, polybrominated diphenyl ethers, novel brominated flame retardants, musks, perfluorinated compounds, currently used pesticides, pharmaceuticals and personal care products). Secondly, 'Individual Compound Information Sheets (INCISE)' contained essential and relevant information on the individual target compounds. These SOPs which were designed to simplify the identification and application of the developed methods by other research groups and laboratories, and to facilitate the effective monitoring and control of the targeted compounds, are compiled in a publicly available SOLUTIONS deliverable [71]. Kuzmanovic et al. [40] applied some of these multiresidue methods in the rivers of the Iberian Peninsula.

The analytical efforts mentioned above are restricted to target chemicals that are either known or suspected to occur and for which analytical standards are commercially available. To extend the universe of chemicals considered during water monitoring (for illustration see Fig. 1), we further explored novel routes of non-target chemical analysis using modern high-resolution mass spectrometry techniques.

\section{Suspect screening and non-target analysis}

While in target analysis, the analytes are known and standards are available, thus allowing for compound-specific method optimizations, in suspect analysis, standards are not necessarily available up front and in non-target analysis, even the structures of the compounds detected are not necessarily known [36]. Daily non-target

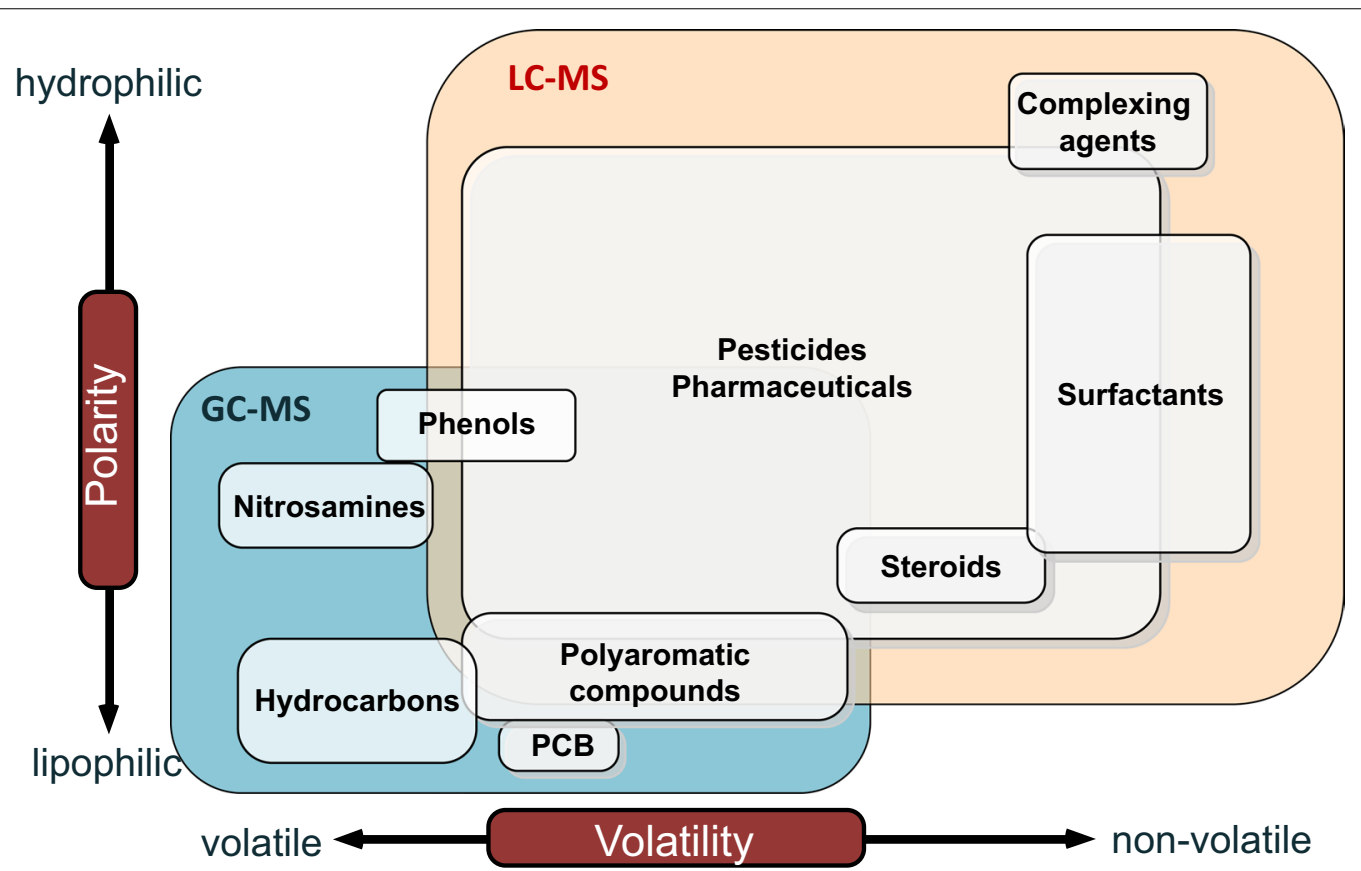

Fig. 1 Domains of GC-MS and LC-MS techniques for emerging contaminants in terms of hydrophobicity and volatility. Atmospheric pressure techniques result in increasing overlap for both LC and GC-MS. The figure follows the concept of Ternes et al. [63] 
monitoring of Rhine river water revealed its potential to support monitoring, revealing significant time series of unknown compounds at high intensities, for which the structures were subsequently elucidated and ultimately identified as industrial contaminants (Fig. 2 in [34]).

A major bottleneck hindering the widespread use of non-target analysis in RSPB identification results from the currently time-consuming and limited means of identifying compound structures out of the data-rich and complex mass spectral information. Within the SOLUTIONS project, we developed a workflow (Fig. 2) that ensured a systematic approach towards unknown compound identification, utilizing as much open data and software as possible. The workflow has been applied in several case studies, including the formation and elimination of transformation products through wastewater treatment including ozonation and several post-treatment steps [59]. Hierarchical cluster analysis across all treatment steps indicated that only a small portion of the non-target signals (9\%) was formed during ozonation, while $54-83 \%$ of these signals were removed during posttreatment. The effectiveness of the advanced treatment and comparison of different post-treatment steps could already be demonstrated by bulk characterization parameters such as peak numbers or overall reduction in mass. The results of effect-based tools supported these conclusions regarding the effectiveness of treatment.

Beyond the identification of new compounds, NTS data may be used to characterize chemical contamination up to a continental scale by considering "chemical fingerprints" in surface water samples that may relate back to specific sources of chemicals or toxicity profiles [12]. The rapid progress in technology and distribution of powerful LC- and GC-HRMS technology for comprehensive NTS, open data repositories for digital freezing of samples together with the increasing availability of tools for big data evaluation and pattern analysis will pave the way for a more comprehensive assessment of chemical contamination in the near future.

\section{Deconstructing mixtures into bioactive components}

An approach is needed to identify (bioactive) candidate chemicals in complex mixtures that may be relevant on a larger spatial scale [24, 35]. The goal of a methodology that has been labeled virtual effect-directed analysis (vEDA) [24] is to assist explaining of biological effects by

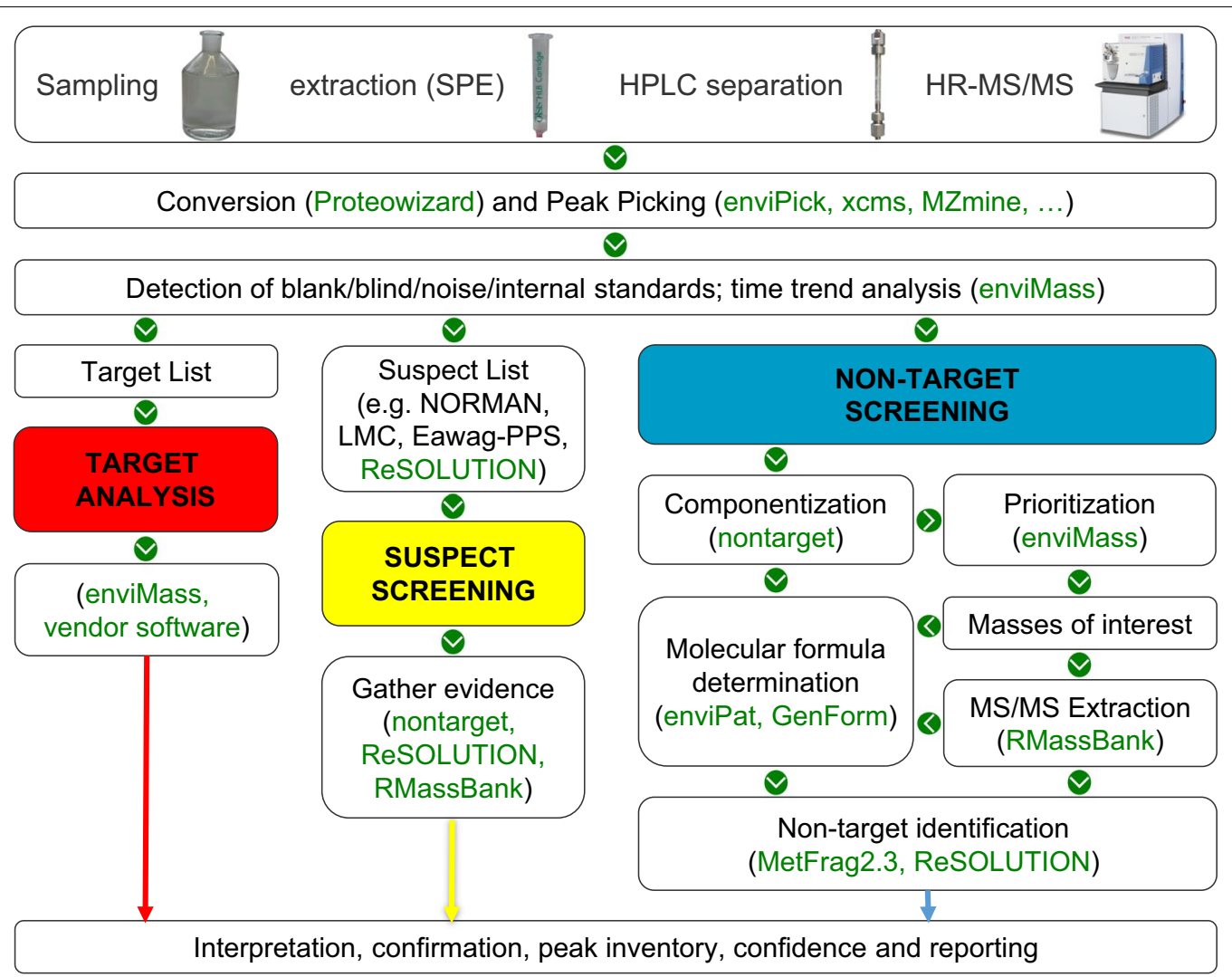

Fig. 2 The SOLUTIONS workflow for structure assignment in target, suspect and non-target analysis (Source: https://solutions.marvin.vito.be/docs/ products_enduser/FS003.pdf) 
reducing the complexity of mixture components via multivariate statistics and pattern recognition methods on large sample numbers using a decomposition approach. This approach is able to handle peaks from non-target analysis, and thus is not restricted to previously known chemicals. Virtual EDA helps to identify peaks that covary with observed biological effects, suggesting these as candidate causative chemicals (Fig. 3). Obviously, this approach does not directly provide cause-effect relationships, but allows hypothesis generation, which must be confirmed using, e.g., literature and database review, calculation of toxic units using quantitative structure activity relationships (QSAR), or a full chemical and effect assessment with reference standards. Successful vEDA generally requires that:

1. The observed effect is caused by a limited (small) number of toxicants among those present in the samples.

2. Sufficient variance (larger than the data uncertainty) of the observed effect and chemical composition patterns occurs across the different samples.

A case study on a time series of mutagenic wastewaters from a mixed industrial and municipal WWTP serves as an example. Varying levels of mutagenicity were detected at different time points over approx. 6 weeks, along with thousands of chemical signals of varying intensity from LC-MS non-target screening. Applying partial least squares analysis, the number of peaks of interest to explain the variability in mutagenicity was reduced to about 200 signals [35]. The overrepresentation (30 times larger) of nitrogen-containing compounds among the selected peaks, along with enhanced mutagenicity in a diagnostic Ames Salmonella stem (YG 1024) suggested aromatic amines as drivers of mutagenicity. After specific derivatization techniques were applied [44], several of these compounds could be identified. The intensity of two peaks, in fact two diaminophenazine isomers, were found to correlate with mutagenicity and were eventually confirmed as the drivers of the observed mutagenicity [45].

\section{Impact assessment}

The ultimate goal of water quality management under the WFD is to ensure a good water quality of European surface and groundwater water bodies (EU directive $2000 / 60 / E C)$. Operationally, this has been separated into the assessment of both a chemical and ecological status, which complicates management actions aiming to reduce the impact of major drivers of degradation [11]. Any approach to identify ecological impacts caused by chemical contamination on community composition has to overcome this divide. Furthermore, approaches need to discriminate the impact of toxic chemicals from nonchemical stressors, which often have a strong impact on community composition. Starting from the contamination perspective, analytically undetected but toxicologically relevant compounds, transformation products and mixture effects may be overlooked in an approach that

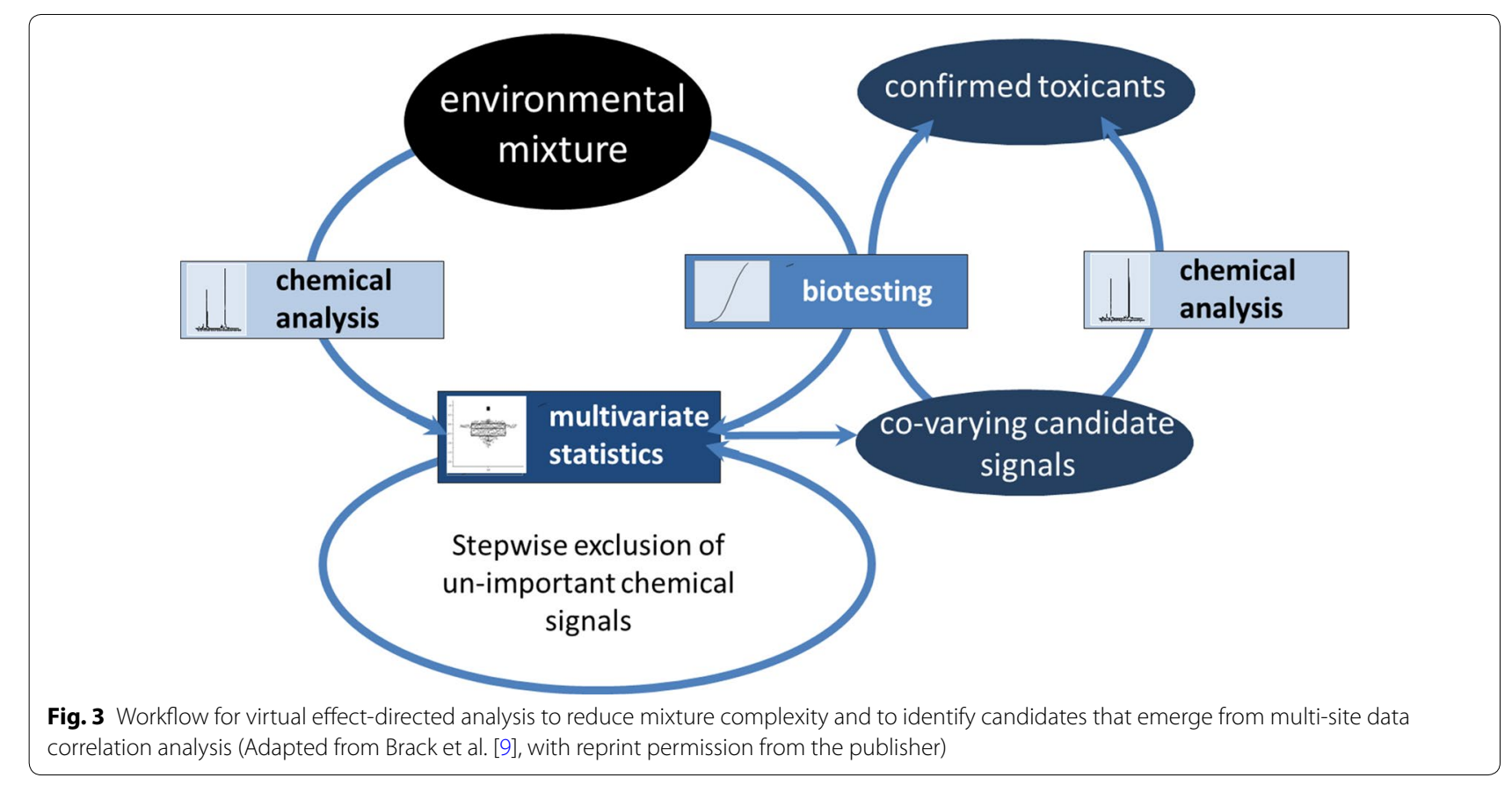


is purely based on target chemical measurements. We explored approaches aiming to render ecological monitoring observations more accessible for diagnosis of potential chemical impacts and amended techniques to link chemical contamination measurements with effect information relevant for assessing biologically adverse effects.

\section{Ecological health status diagnosis}

Monitoring the presence and abundance of different species forms the basis for an ecological status assessment of water bodies. Exposure to toxic chemicals can affect freshwater aquatic life and may lead to shifts in the composition of freshwater communities through the loss of sensitive species. Toxic pressure is, however, not the only possible reason for variations in the health of aquatic biota. Other non-chemical factors such as hydrological conditions or general water quality parameters can have a strong impact on aquatic ecology, possibly confounding diagnostic efforts.

Chemically induced shifts in community composition are expected to correlate with chemical exposure and can, thus, be used as detectors. Additionally, considering species traits, i.e., biological characteristics relevant for the elucidation of chemical effects, rather than using the occurrence of different species, can help to increase diagnostic power or ecological information [66]. Therefore, an approach statistically separating chemical from non-chemical impacts on taxonomy or traits-based community composition was developed and tested in SOLUTIONS [56]. It builds on the variance partitioning technique of Borcard et al. [7].

Prerequisites for the application of the variance partitioning method are chemical exposure data and information about other stressors such as general water quality parameters $(\mathrm{pH}$, water hardness, nutrient levels, etc.) or hydro-morphological characteristics. A comprehensive statistical analysis of the relative importance of the different stressor groups for community composition can be obtained by a stepwise refinement of the explaining factors, increasing the resolution of the method by 'zooming' into single factor groups $[56,57]$. In addition to the correlative analysis of the impact on variance, groups of chemicals (e.g., using class or modes-of-action) can be ranked and statistically tested concerning their impact on the composition of species or their properties across a number of sampling sites using Monte Carlo permutation testing. The methodology can be used to check whether measured chemicals show a statistically significant influence on existing community composition data.

This method was applied for a data-rich case study from the 3rd Joint Danube Survey, where information on the community compositions of aquatic macroinvertebrates, concentrations of about 300 organic pollutants and data on habitat characteristics, hydromorphology and general water quality parameters were available for 55 sampling sites along the whole Danube [56]. In this study (Fig. 4), variation of structure and trait composition of the invertebrate community was mainly explained by habitat and water quality parameters, whereas hydromorphological alterations were found to play a less important role. Physico-chemical water quality parameters explained a larger part of the variation in the invertebrate community, compared to metals or organic contaminants (Fig. 4). Nevertheless, 8.7 and $12.5 \%$ of the variation in the community compositions in this study were significantly correlated with organic pollutants, while the 'flat' exposure profile along the Danube sampling sites probably impaired the identification of a larger share [56]. This evaluation is dependent on the number of chemicals analyzed (here, 227 metals and organic compounds were considered) and the availability of toxicity data (75\% of which had to be estimated using QSARs). Accounting for more contaminants and using more measured effect data would, therefore, also lead to an increased contribution. A second application on data from the Swiss EcoImpact study confirmed the usability of the variance partition approach. Up to $12.7 \%$ of variation in the community data was explained by chemical pollutants [14]. A related partition of variance exercise (redundancy analysis-RDA) was applied to Iberian Rivers [57]. The total explained variance on the biofilm and invertebrate communities was $86 \%$, where $2.2 \%$ was directly attributed to organic micropollutants, $5.7 \%$ to land uses, and $10.6 \%$ of the environmental variables (nutrients, altered discharge, dissolved organic matter). The total shared variance of the three groups of stressor variables amounted to $41 \%$.

The developed methodological approach allows additional information to be extracted by pooling different existing data. Moreover, it can be standardized and may be applied on a routine basis.

\section{Effect detection using bioassay panels}

Clearly, using ecological data to determine the link to specific chemical pollutants will remain elusive and of limited resolution for the foreseeable future due to the lack of diagnostic power of existing methods and/or the presence of multiple stressors, e.g., in urbanized areas. Bioassays are a complementary method to improve the detection of potential adverse effects from toxicologically relevant compounds and to help account for combination effects from mixture exposure $[1,13,18,70]$. Moreover, if we strive to exit from the uncertainty bias (i.e., drive effect assessments by uncertainty factors to bridge the knowledge gaps), it is vital to add effect-based 
A. Habitat characteristics

B. Hydromorphological alterations

C. Water quality parameters and TUs for each contaminant group

Taxonomic composition Traits
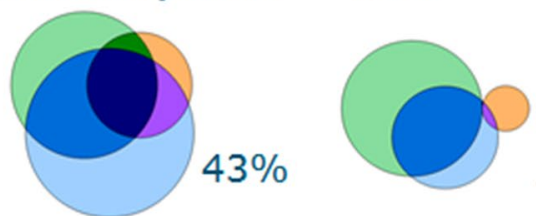

$33 \%$

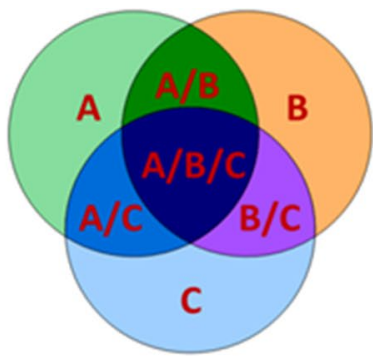

A. Basic water quality parameters

B. Heavy metals TUs

C. Sum of TUs for organic micro-pollutants

Taxonomic composition Traits

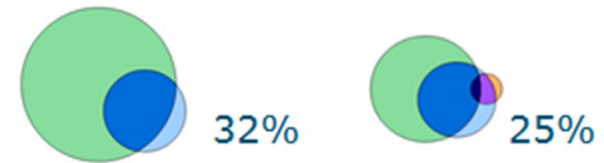

\begin{abstract}
A. TUs insecticide, herbicide and fungicides
B. Pharmaceuticals, HPCPs and miscellaneous compounds
\end{abstract}

C. TUs industrial chemicals

Taxonomic composition Traits

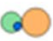

$9 \%$

$12 \%$

Fig. 4 Results of the variation partitioning analyses from three consecutive analyses (panels from top to bottom) for data from the Joint Danube Survey 3. Environmental parameters were used as explanatory variables for biological outputs analyzed as taxonomic composition and as traits composition. Consecutive analyses grouped explanatory variables according to different levels of specificity (Adapted from Rico et al. [56], with reprint permission from the publisher)

observations to the samples being assessed for chemical contamination.

Comprehensive analysis of uncharacterized but biologically active mixtures of organic contaminants requires additional effect-based approaches to be adopted for analyzing enriched water samples, as a complement to chemical analysis [25, 27]. We developed a systematic approach for capturing anticipated effects from such complex chemical mixtures. First, we compiled lists of water contaminants found in monitoring studies and translated these into mode-of-action (MoA) categories [15]. These MoAs were then used to devise panels of bioassays designed to comprehensively capture biological effects of chemicals expected in water [1, 23]. Subsequently, bioassay panels were applied to single water contaminants to test the MoA categorizations [48, 49], as well as mixture effect recovery in complex contaminated samples [2] and in various monitoring case studies [38, $47,49,52,65]$.

The construction of a comprehensive diagnostic bioassay panel that captures all known MoAs using a specific bioassay is not yet realistic. For two-thirds of the 426 organic chemicals detected in monitoring studies of European freshwater, about 100 distinct biological molecular targets were identified and subsequently grouped into 30 categories of MoA. For the remaining chemicals, mostly transformation products, insufficient information was available to allocate a MoA [15]. There are few bioassays (typically, but not exclusively, in vitro assays) that are suitable for the proposed monitoring and capable of detecting specific biological effects beyond endocrine activity, photosystem II inhibition, mutagenicity and metabolic activation. Thus, for effect categories such as neurotoxicity or inhibition of mitosis and sterol biosynthesis, relevant water contaminants could escape attention [58].

At this stage, we suggest using modular panels of bioassays in effect-based water monitoring (Fig. 5). A module consists of different bioassays that allow similar interpretation in terms of specificity of exposure and effect observations. Different modules may be combined, depending on the monitoring scope, which may range 

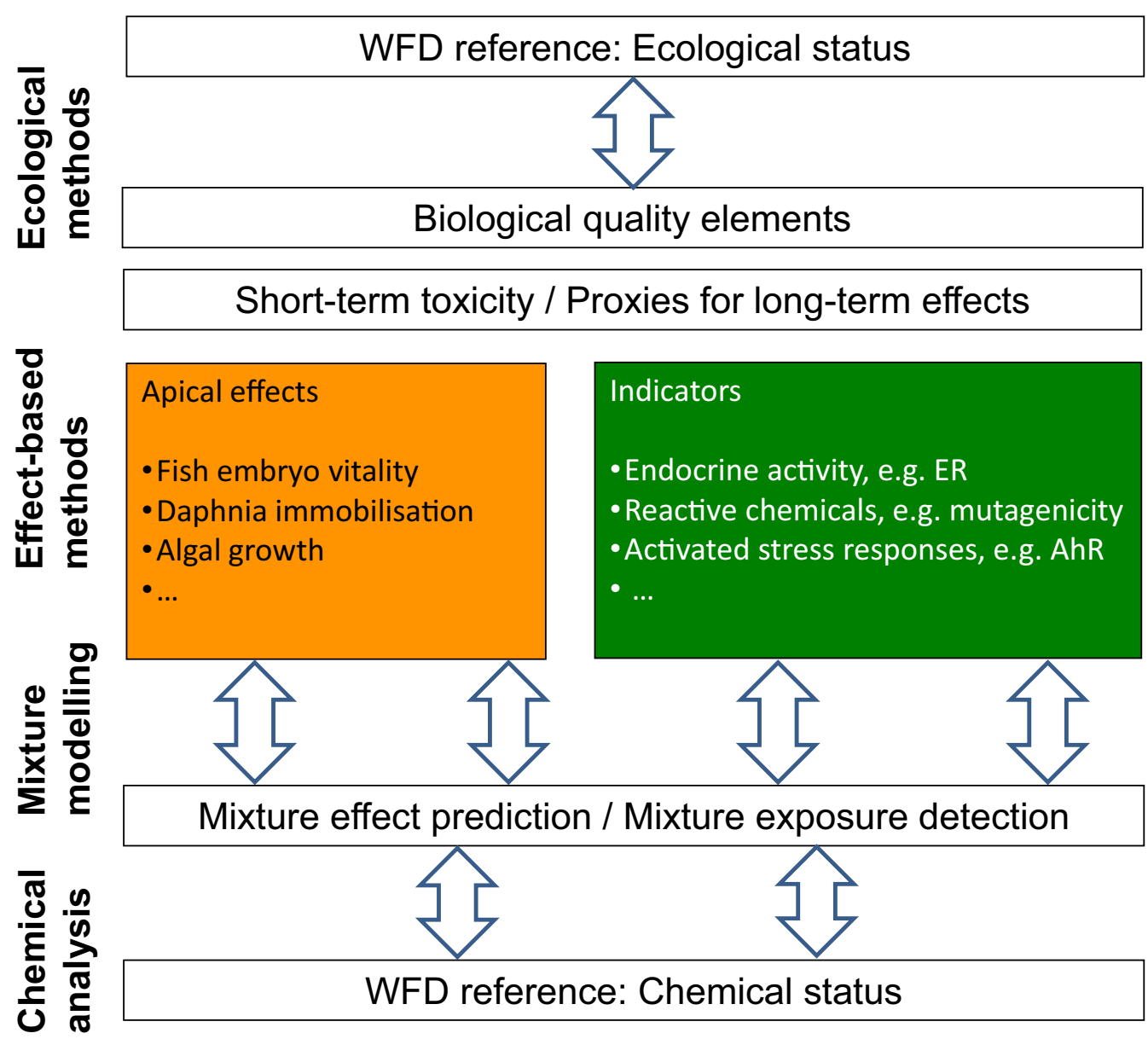

Apical effects

- Fish embryo vitality

- Daphnia immobilisation

- Algal growth

-...
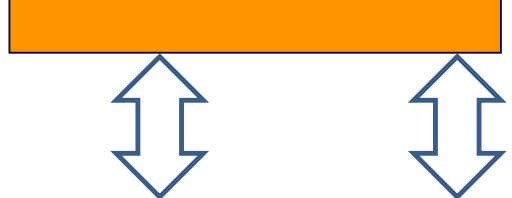

Mixture effect prediction / Mixture exposure detection

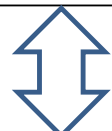

WFD reference: Chemical status

Fig. 5 Effect-based methods for water monitoring and its complementarity to chemical and ecological observations. The analysis of RBSPs would follow the same assessment approach, but is reported under the WFD ecological status. This figure extends concepts from Brack et al. (in press) and EEA [23]

from surveillance of individual contaminants or critical effects through to comprehensive status assessment. Modules are, thus, distinct from a tiered testing scheme as used in environmental risk assessment for single compounds. The first module comprises a set of short-term exposure organism assays, to capture an array of apical effects. While the diagnostic value for exposure will be restricted to the discrimination between phyla-specific effects, the assessment can be directly related to biological quality elements used in ecological status assessment. Thus, if the monitoring question relates to determining whether a compromised ecological status may be caused by chemical contamination, effect-based tools from the module using endpoints easily related to biological quality elements (fish, macroinvertebrates, phytoplankton, macrophytes) may be the first choice. The second module comprises of bioassays, cell- and organism based, that detect specific chemical-biosystem interactions that are indicative of chronic effects. Depending on our knowledge about the toxicodynamics related to a certain chemical-biosystem interaction, the assay responses may be used to either detect exposure for a defined group of compounds or indicate long-term effects, which may be overlooked when using short-term assays only. Here, a driving objective for the selection of bioassays would be the surveillance of drinking water abstraction and safeguarding against potential human health effects.

Indication of a long-term effect after exposure to a compound group may be performed through an established adverse outcome pathway, e.g., endocrine disturbance. The associated bioassays may be regarded as indicative for a defined long-term effect. For example, receptor-mediated endocrine disruptive activity of various types can be detected with high sensitivity using receptor-based assays that are either cell based or employ transgenic organisms. While a detailed discussion of AOPs is out of the scope of the current manuscript, it is fair to say that currently, we lack fully established AOPs 
ready for ecotoxicological application. It is, however, possible to integrate exposure detection across a larger number of compounds for stress response bioassays such as oxidative stress response or mutagenicity. This builds on the detection of signals downstream of a primary chemical-biosystem interaction and while they detect exposure, it remains context dependent whether the responses indicate compensation of or propagation towards adverse effects. Similarly, metabolic activation assays, such as AhR binding assays, which are typically promiscuous in their binding specificity, are known to elucidate pleiotropic responses and are, thus, easiest to use for mixture exposure detection.

Typical additional factors that determine the bioassay selection comprise rapidity, sensitivity, adequacy, statistical robustness, high reproducibility, accepted level of standardization, automated protocol, and demonstrated use for monitoring purpose, potential for inference, cost effectiveness and degree of representativeness as a biological proxy. Again the purpose of the study is most important, e.g., if assessment of contamination by lipophilic compounds is of concern, dioxin-like effects measurable with different types of bioassays, such as AhR receptor-binding assays, will be important. However, if more polar and water-soluble compounds are of concern, these assays are unlikely to detect much bioactivity. To foster the application of the bioassays applied in the case studies summarized above, one may refer to the standard operating procedures documented in the supporting information of Neale et al. [48, 49].

Bioassay findings cannot always be explained by monitored chemicals, as demonstrated in several case study investigations in surface [26, 38, 47, 49], and groundwater [39]. This is particularly true for assays indicative of more integrative effects. Therefore, it is useful to develop bioassay-specific trigger values that can serve for the assessment of observed effects at a given level of sample dilution/concentration. Whole effluent testing using bioanalytical methods, such as fish embryo, daphnia, luminescent bacteria or algae testing is performed already for wastewater surveillance in the German Waste Water Ordinance [32] under the Federal Water Act [31]. This regulation adopts the EU-WFD and provides a reference case for effect-based monitoring and assessment. Here the lowest inhibitory dilution in an apical bioassay deemed acceptable for a specific type of effluent is defined. In SOLUTIONS, the single chemical fingerprinting and mixtures studies were used to derive bioassay-specific effect-based trigger values (EBT), which would allow assessment of other effects beyond apical effect-based monitoring findings. The derivation of a more generalized approach for setting EBT values was based on the European environmental quality standards
(AA-EQS), on data generated in SOLUTIONS, and on literature data [28]. The derived EBTs are still preliminary, because bioanalytical effect data are generally only available for chemicals with existing EQS. More single chemical data must be obtained for the different assays before specific EBT values can be considered ready for harmonization.

\section{Cause-effect relationships}

Eventually, when management options for water contamination are considered, the establishment of causeeffect relationships may be essential for determining appropriate actions. Strategies to establish causal relationships between multiple contaminants and deleterious biological effects in SOLUTIONS were explored in terms of different levels of biological outcomes. Firstly, we operationalized the WFD concept of biological quality elements using effect-based methods, identifying chemicals causing biological effects observed for water samples employing sample fractionation and analytical techniques, an approach called effect-directed analysis (EDA) [9]. Secondly, we synthesized different lines of evidence (LOE) (cf. [16]) to explain observable biological effects on communities in the field, which we call ecology-directed analysis.

\section{Effect-directed analysis}

Despite the presence of mixtures of multiple compounds in environmental media, theoretical considerations and experimental findings suggest that the overall risk to individual organisms or populations of a species may be driven by only a few mixture components [3]. Thus, identification of the most significant chemicals contributing to observed effects will help to establish the corresponding cause-effect relationships and provide focus for potential management measures.

In some cases, well-known chemicals can explain observed biological responses (e.g., estrogenicity detected in surface water using in vitro assays often results from only a few natural and synthetic steroid estrogens such as estrone, estradiol, and ethinyl-estradiol) [33, 37, 38, 47]. However, in other cases routinely analyzed chemicals cannot explain observed biological responses (e.g., [26, $47,49]$. In these cases, bioassays provide a more comprehensive picture of the chemical burden in the aqueous environment. Efforts in the SOLUTIONS project, therefore, aimed to better understand which (organic) chemicals contribute to observable effects and what fraction of the effect is caused by unidentified chemicals, using a stepwise approach shown in Fig. 6.

When determining drivers of mixture toxicity using this approach, initially chemical target monitoring data should be evaluated using component-based mixture 


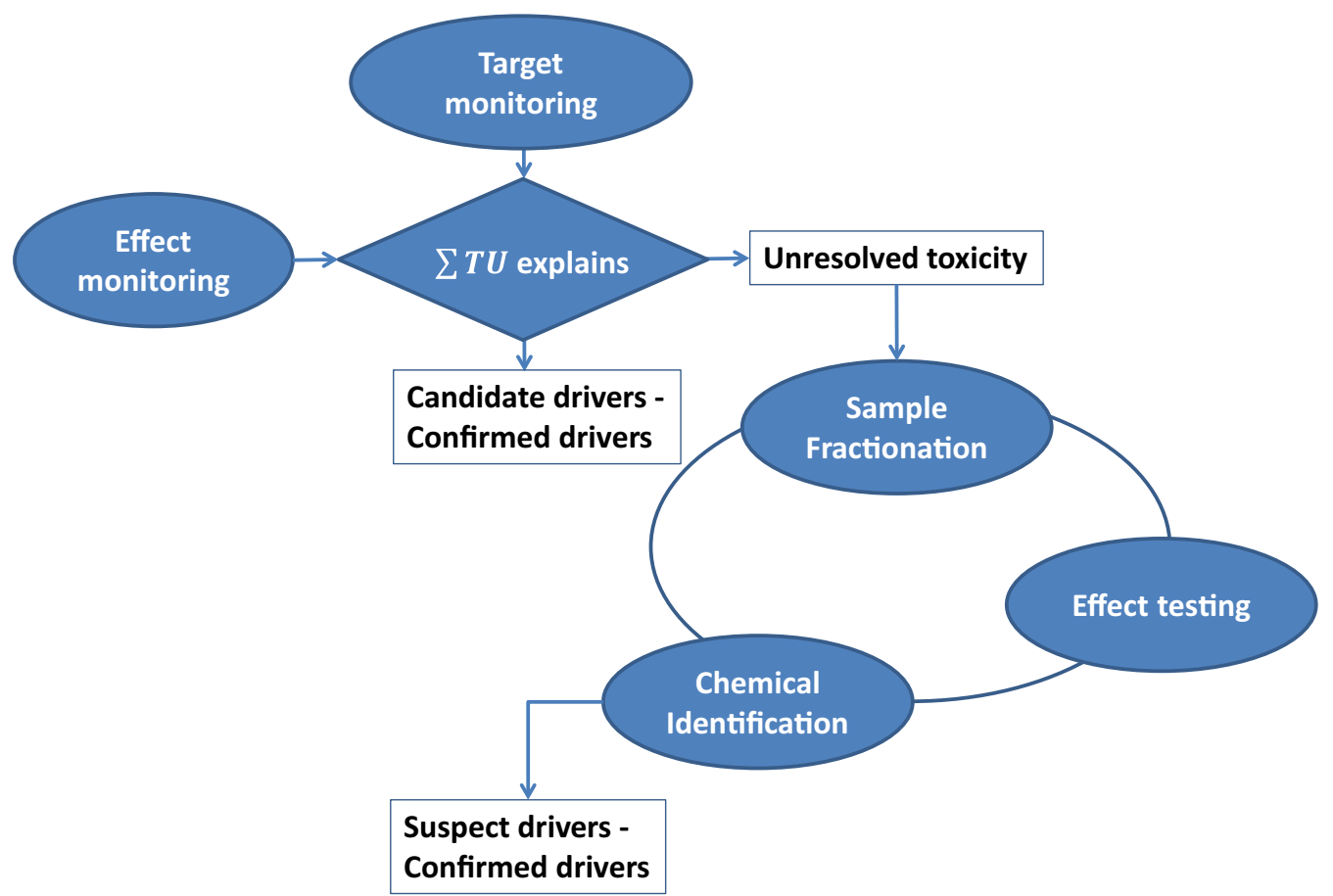

6 Stepwise identification of cause-effect relationships between chemical contaminants and selected biological effects using $\Sigma T U=$ sum of toxic units and effect-directed analysis. The confirmation of candidate or suspect drivers requires an additional step

toxicity predictions. For chemicals with known effect concentrations (ECs), Toxic Units (TU) can be calculated as the ratio between environmental concentrations and ECs for a specific water quality element (e.g., phytoplankton or invertebrate fauna). This can be used to identify candidate drivers of toxicity. Assuming concentration addition as a model for mixture toxicity, the sum of toxic units $(\Sigma T \mathrm{TU})$ can be used as a default approach [5]. This step may already provide a basis for a tentative prioritization of sites and rivers of concern, as well as for the identification of sensitive biological quality elements. Existing chemical monitoring data may subsequently be compared with effect-based monitoring using a panel of biological endpoints (see above), that may be adapted for specific diagnostic purposes. More recent work has shown that it may be reasonable to expect a full mass balance for specific responses, for example receptormediated effects. An iceberg model [62] can be used to quantify the differences between expected (componentbased) and observed (bioassay-based) mixture effects.

Subsequently, a full, unbiased EDA investigation can be used to investigate whether unidentified chemicals account for unexplained biological effects. The EDA methodology works without any previous information on the types and sources of pollution. The data evaluation and investigations suggested in the first step will help to decide if EDA should be applied to unravel any remaining unexplained toxicity. Basically, EDA reduces environmental sample extracts to less complex mixtures or individual compounds by fractionation and subsequent bioassay-directed selection of subsamples, so that relevant toxicants can be isolated and identified by chemical analysis [9]. Finally, identified toxicants need to be confirmed as the cause of the measured effect. This is carried out using analytical confirmation of identified structures as well as effect confirmation by testing neat standards and artificial mixtures. Furthermore, it may involve mixture toxicity modeling, and finally hazard confirmation, which should account for effects at higher levels of biological organization, such as populations and communities under realistic exposure conditions [10]. The power of this approach has been demonstrated, e.g., for anti-androgenic effects detected in vitro in a small river in Germany impacted by treated wastewater [43]. Parallel fractionation with different stationary phases together with testing and chemical screening of the resulting fractions was able to reduce the number of candidate peaks to very few peaks, eventually identifying and confirming the fluorescent dye coumarin 47 as the driver of the measured effect in vitro and in vivo in Medaka embryos. Site-specific compounds from local economic and social activities, such as in this example, typically go 
unrecognized in chemical analyses, as well as in ecological monitoring.

Effect-based monitoring combined with EDA and mixture effect experiments also support the identification and understanding of effects driven by the interaction of different compounds. This has been demonstrated by partial unraveling of mutagenic effects in the river Rhine, establishing synergistic effects of industrial aromatic amines with natural carboline alkaloids, which co-occur frequently in river water [46].

As EDA is a time- and resource-consuming approach, the problem formulation should be carried out with great care, prerequisites thoroughly checked, and the methods and approaches selected appropriately. Conducting a full EDA to identify specific toxic compounds may not be needed, if abatement options that reduce the toxic effect can be identified. In these cases, the solution to an existing problem can be found and implemented without the final knowledge of the actual causative agents (as also discussed above). Applying an EDA is meaningful if

1. Effects can be observed for organic extracts of environmental samples (also implying the cause may be organic chemicals);

2. The observed effects can be related to a specific toxicological endpoint, which can be assessed using bioassays applicable to environmental sample extracts and fractions within a reasonable time and cost scale;

3. The observed effect is likely caused by a limited (small) number of toxicants amongst those present in a sample, i.e., only a small number of active fractions are detected in EDA. This is mostly the case for bioassays with specific, often receptor-mediated responses.

\section{Ecology-directed analysis}

The WFD aims to ensure a good ecological status for European water bodies, as well as a good chemical status. A major challenge hindering implementation of appropriate water management measures is to differentiate chemical-induced ecological impacts from, e.g., the ecological impacts of habitat change. This requires that the aforementioned lines of evidence are tied together with data from biomonitoring efforts, higher tier ecotoxicological assessments and in situ studies. To tease out the causal link between the occurrence of complex chemical mixtures and ecologically relevant effects, we developed and explored a multiple LOE approach [6]. The following four LOEs were considered:
1. Chemical occurrence data for the sites of interest, analyzed with predictive mixture modeling approaches to indicate potential mixture risks;

2. Bioanalytical data from samples and fractioned subsamples studied to establish concentration-effect relationships;

3. In situ functional responses, comparatively assessed at potentially polluted sites and reference situations; and

4. Surveys on species and trait abundance as well as population and community structure (biodiversity) at potentially impacted sites and reference sites.

This approach provides an adaptive and integrative method that systematically synthesizes the evidence from the different LOEs and provides optimum decision support for an ecologically oriented water management.

The overall status of each of the four individual LOEs is condensed and categorized into classes that indicate clear or moderate signals of pollution-driven impacts (Fig. 7). In an application example, data obtained for the single LOEs from the 3rd Joint Danube Survey were analyzed [6]. Results from in-depth chemical analyses of water samples (see above) were used for predictive mixture toxicity modeling ( $\Sigma \mathrm{TU})$. Results from a battery of in situ biomarkers in sentinel fish (Alburnus alburnus and Neogobius sp.) [17], including mainly markers for exposure (enzyme activities for biotransformation, oxidative stress and neuronal activation) and effects at cellular levels (genotoxicity), were analyzed and aggregated using an index for the average biomarker response. Finally, taxonomy- and trait-based analyses of fish and macroinvertebrate community data were performed to indicate ecological impacts [56]. A particular problem was the limited spatial overlap between sampling sites for the different LOEs. Results from a suite of in vitro bioassays, performed with extracts from LV-SPE and equilibrium passive sampling, were considered [47] but could not be fully included due to the spatial mismatch. An independent analysis regarding the evidence of genotoxic bioactivity was performed instead [61].

Despite these constraints, the toolbox application helped to identify a number of sites in the Danube where component-based mixture risk predictions, biomarker responses and community level responses, consistently indicated a chemical-driven impact. Many of the Danube sampling sites show clear indications of anthropogenic impacts, and in all cases the estimated toxic pressure suggests that pollutants are likely a contributing cause. However, the functional in situ responses for many sites indicate that the link from functional measures of toxic pressure to community effects is not as clear as anticipated when comparing chemical pressure and 


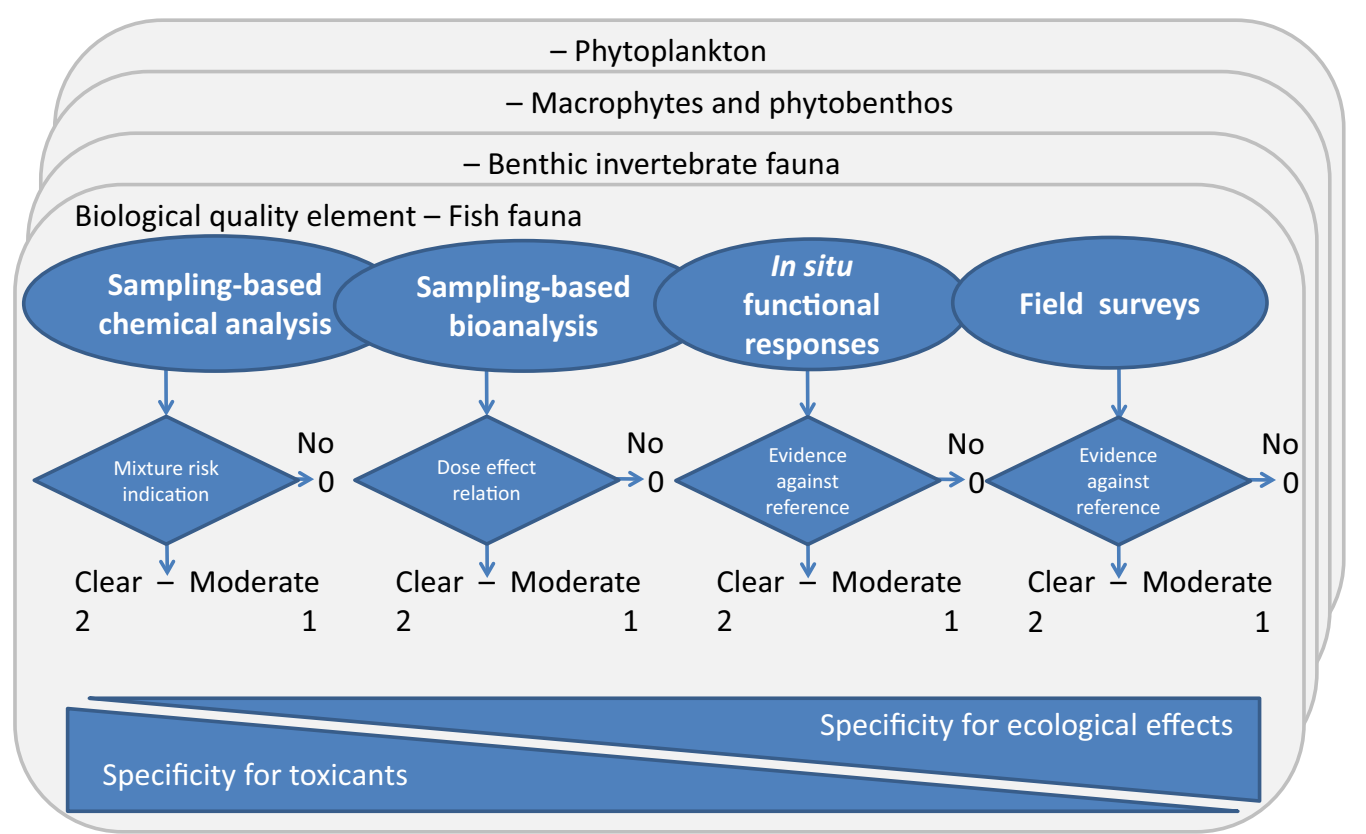

Fig. 7 Aggregating information from different lines of evidence (LOEs) into a weight of evidence matrix specific for each biological quality element to support cause-effect relationships between chemical contamination and ecological effects; Spectrum of outcomes between chemistry (mixture toxicity potential) and ecology (effects at community levels). In situ responses can link between those ends; four main LOEs, including the elements of evidence for which additional information may be included. The in situ LOE includes tests from the sub-organism to the community level. Mechanistic information for different action by pollutants is conserved by differentiation among the LOEs for the different biological quality elements

community effects. Here, biomarkers and average biomarker responses could provide additional information to support the overall evaluation of the chemical and ecological quality of water bodies.

The LOE-based approach transformed the multidimensional JDS3 data into a simplified matrix suitable for water managers and decision-makers, without losing crucial information. This matrix can serve as a basis for conclusive statements about the impairment of the ecological status at the various sites. It also pinpoints critical data gaps, which might stimulate and guide future chemical monitoring and ecological testing.

\section{Perspectives for water quality monitoring}

Given the dynamics of chemical innovation, production, consumption, use, disposal, and consequent emission into the aquatic environment, the challenge for a successful amendment and implementation of the European Water Framework Directive [29] is to define more specific strategies for protecting and enhancing the status of aquatic ecosystems. In particular, strategies for identifying river basin specific pollutants, improvements in the diagnostics of ecological impacts and more powerful approaches for establishing causal links between chemical and ecological assessments are required.
By synthesizing the developments within the SOLUTIONS project in terms of water sampling techniques, chemical analytical and effect-based methods and describing their application to various case studies, we can now offer advanced approaches for water quality monitoring and assessment. In particular, we can overcome the focus on a few selected pollutants that is so obviously inadequate to achieve the goals of the WFD. Instead of disconnected environmental assessment of compounds and products for pesticidal, biocidal, pharmaceutical, industrial and other uses, a more comprehensive assessment approach is now a realistic option. In the field of economic instruments, well-developed and moderately priced bioassays could also serve in a modernization of, e.g., WWTP effluent taxation. Some European countries have already implemented effluent charges [21]. One perspective could be to replace one bioassayBOD - with another bioassay, e.g., on endocrine disruption or mutagenicity. Such a shift could be designed to be cost-neutral to the current situation in the setting of new tariffs. This would mark a change in the focus from impacts related to direct oxygen depletion (often a solved issue) to toxicity-related impacts (an emerging issue) and provide an incentive for WWTP managers to reduce such emissions. 
Given the technological accomplishment made with the joint efforts of the SOLUTIONS consortium and other efforts in the last years, it is now possible to consider mixture occurrence and mixture toxicity in aquatic organisms and ecosystems. The real impact on improving water quality will ultimately be measured by policy uptake for amending monitoring demands in a revised Water Framework Directive.

We believe that more balanced generation and utilization of exposure and effect data helps to foster evidencebased water quality assessments. Moreover, we are convinced that such an improved knowledge base will help to (i) develop more streamlined approaches to link chemical and ecological status monitoring and (ii) focus resources on major management tasks. Application of the advanced tools developed for comprehensive chemical fingerprinting and toxicity profiling, to test the proposed strategy, is still required. Nonetheless, the experience gained from SOLUTIONS will substantially help in supporting this development along with other international networks such as the NORMAN network on emerging pollutants.

\begin{abstract}
Abbreviations
AA: annual average; AOP: adverse outcome pathways; BEQ: bioanalytical equivalent concentration; BQE: biological quality elements; CIS: Common European implementation strategy; EDA: effect-directed analysis; EQS: environmental quality standard; EU: European Union; GC-MS: gas chromatography mass spectrometry; GC-MS/MS: gas chromatography tandem mass spectrometry; HPCCC: high-performance counter current chromatography; JDS3: Joint Danube survey monitoring study 2013; KE: key event; LC-MS: liquid chromatography mass spectrometry; LC-HRMS/MS: liquid chromatography high-resolution tandem mass spectrometry; LOE: lines of evidence; LVSPE: large-volume solid phase extraction; MIE: molecular initiating event; MoA: mode-of-action; NTS: non-target screening; PNEC: predicted no-effect concentration; QSAR: quantitative structure activity relationship; RBSPs: river basin-specific pollutants; RDA: redundancy analysis; SOLUTIONS: EU project (http://www.solutions-project.eu); SOP: Standard Operating Procedure; TU: toxic units; $\Sigma T U$ : sum of toxic units; WFD: Water Framework Directive; WWTP. waste water treatment plant.
\end{abstract}

\section{Authors' contributions}

RA designed and drafted the original manuscript with major support by MK. The concepts developed for the different strategies discussed were revised with the support of WB, RMB, WB, BIE, AF, LMH, BNJ, and MLA. All other coauthors, contributed intellectually to various methodological and technical aspects of the MS and re-analyzed work of the case studies. Also, every coauthor provided amendments and revision to the third draft manuscript. All authors read and approved the final manuscript.

\footnotetext{
Author details

${ }^{1}$ UFZ-Helmholtz Centre for Environmental Research, Permoserstr. 15 04318 Leipzig, Germany. ${ }^{2}$ Institute for Environmental Research, RWTH Aachen University, 52074 Aachen, Germany. ${ }^{3}$ Office of Research and Development, Atlantic Ecology Division, United States Environmental Protection Agency, Narragansett, RI, USA. ${ }^{4}$ Center for Applied Geoscience, Eberhard Karls University Tübingen, 72074 Tübingen, Germany. ${ }^{5}$ Alterra, Wageningen University and Research Centre, P.O. Box 47, 6700 AA Wageningen, The Netherlands. ${ }^{6}$ Environment and Climate Change Canada, Burlington, ON, Canada. ${ }^{7}$ Sophus Bauditz Vej 19 B, 2800 Kgs. Lyngby, Denmark. ${ }^{8}$ Water and Soil Quality Research Group, Institute of Environmental Assessment and Water Research (IDAEACSIC), Jordi Girona 18-26, 08034 Barcelona, Spain. ${ }^{9}$ Unité d'Ecotoxicologie
}

in Vitro et in Vivo, UMR-I 02 SEBIO, Institut National de l'Environnement Industriel et des Risques INERIS, 60550 Verneuil-En-Halatte, France. ${ }^{10}$ Department of Biological and Environmental Sciences, University of Gothenburg, Carl Skottbergs Gata 22b, 40530 Gothenburg, Sweden. ${ }^{11}$ Masaryk University-Research Centre for Toxic Compounds in the Environment (RECETOX), Kamenice 753/5, 62500 Brno, Czech Republic. ${ }^{12}$ Eawag, Swiss Federal Institute of Aquatic Science and Technology, 8600 Dübendorf, Switzerland. ${ }^{13}$ Australian Rivers Institute, Griffith School of Environment and Science, Griffith University, Southport, QLD 4222, Australia. ${ }^{14}$ LCSB, University of Luxembourg, 6 Avenue du Swing, 4367 Belvaux, Luxembourg. ${ }^{15}$ University of Novi Sad, Faculty of Sciences, Trg Dositeja Obradovića, 321000 Novi Sad, Serbia. ${ }^{16}$ WatchFrog, Bâtiment Genavenir 3, 1 Rue Pierre Fontaine, 91000 Evry, France. ${ }^{17}$ Faculdade de Tecnologia, FT-UNICAMP, Universidade Estadual de Campinas, Limeira, SP 13484-332, Brazil.

\section{Acknowledgements}

The SOLUTIONS Project is supported by the Seventh Framework Programme (FP7-ENV-2013) of the European Union under Grant Agreement No. 603437. G.A. Umbuzeiro thanks FAPESP Projects 2013/16956-6 and 2015/24758-5. We like to thank all partners for their continued efforts in making this project a success story.

\section{Competing interests}

All authors declare that they have no competing interests.

\section{Availability of data and materials}

This work is an aggregating synthesis project and contains in large parts reflections of various specific methodological work and case studies. The availability of data is provided through reference to the original publications and where not yet published the relevant deliverables will be made publically available through the SOLUTIONS website (https://www.solutions-project.eu/) as referenced specifically.

\section{Consent for publication}

I, the corresponding author, have written consent for publications from all co-authors.

\section{Ethics approval and consent to participate}

There are no issues in the reported work that required ethic approval in any of the contributing institutions. Consent on participation was obtained from all co-authors.

\section{Funding}

The SOLUTIONS Project is supported by the Seventh Framework Programme (FP7-ENV-704 2013) of the European Union under Grant Agreement No. 603437. G.A. Umbuzeiro thanks 705 FAPESP Projects 2013/16956-6 and 2015/24758-5.

\section{Publisher's Note}

Springer Nature remains neutral with regard to jurisdictional claims in published maps and institutional affiliations.

Received: 26 November 2018 Accepted: 30 January 2019

Published online: 19 February 2019

\section{References}

1. Altenburger R, Ait-Aissa S, Antczak P, Backhaus T, Barcelo D, Seiler T-B, Brion F, Busch W, Chipman K, Lopez de Alda M, de Aragao Umbuzeiro G, Escher BI, Falciani F, Faust M, Focks A, Hilscherova K, Hollender J, Hollert $H$, Jaeger F, Jahnke A, Kortenkamp A, Krauss M, Lemkine GF, Munthe J, Neumann S, Schymanski EL, Scrimshaw M, Segner H, Slobodnik J, Smedes F, Kughathas S, Teodorovic I, Tindall AJ, Tollefsen KE, Walz K-H, Williams TD, Van den Brink PJ, van Gils J, Vrana B, Zhang X, Brack W (2015) Future water quality monitoring - adapting tools to deal with mixtures of pollutants in water resource management. Sci Total Environ 512:540-551

2. Altenburger $R$, Scholze $M$, Busch W, Escher BI, Jakobs $G$, Krauss M, Krüger J, Neale PA, Aït-Aïssa S, Almeida AC, Seiler T-B, Brion F, Hilscherová K, Hollert H, Novák J, Schlichting R, Serra H, Shao Y, Tindall AJ, Tolefsen KE, de 
Aragão Umbuzeiro G, Williams TD, Kortenkamp A (2018) Mixture effects in samples of multiple contaminants-an inter-laboratory study with manifold bioassays. Environ Int 114:95-116

3. Altenburger R, Walter H, Grote M (2004) What contributes to the combined effect of a complex mixture? Environ Sci Technol 38(23):6353-6362

4. Arle J, Mohaupt V, Kirst I (2016) Monitoring of surface waters in Germany under the water framework directive-a review of approaches, methods and results. Water 8:217

5. Backhaus T, Faust F (2012) Predictive environmental risk assessment of chemical mixtures. Environ Sci Technol 46:2564-2573

6. Backhaus $T$, Segner $\mathrm{H}$, Hollert H, Deutschmann B, Van den Brink PJ, Seiler TB, Teodorevic I, Focks A (2017) Solutions external deliverable 13.1 'Diagnostic toolbox for ecological effects of pollutant mixtures'. https://www. solutions-project.eu/project/. Accessed 22019

7. Borcard D, Legendre P, Drapeau P (1992) Partialling out the spatial component of ecological variation. Ecology 73:1045-1055

8. BrackW, Altenburger R, Schüürmann G, Krauss M, López Herráez D, van Gils J, Slobodnik J, Munthe J, Gawlik BM, van Wezel A, Schriks M, Hollender J, Tollefsen KE, Mekenyan O, Dimitrov S, Bunke D, Cousins I, Posthuma $L$, van den Brink PJ, López de Alda M, Barceló D, Faust M, Kortenkamp A, Scrimshaw M, Ignatova S, Engelen G, Massmann G, Lemkine G, Teodorovic I, Walz K-H, Dulio V, Jonker MTO, Jäger F, Chipman K, Falciani F, Liska I, Rooke D, Zhang X, Hollert H, Vrana B, Hilscherova K, Kramer K, Neumann S, Hammerbacher R, Backhaus T, Mack J, Segner H, Escher B, de Aragão Umbuzeiro G (2015) The SOLUTIONS project: challenges and responses for present and future emerging pollutants in land and water resources management. Sci Total Environ 503-504:22-31

9. BrackW, Ait-Aissa S, Burgess RM, Busch W, Creusot N, Di Paolo C, Escher Bl, Mark Hewitt L, Hilscherova K, Hollender J, Hollert H, Jonker W, Kool J, Lamoree M, Muschket M, Neumann S, Rostkowski P, Ruttkies C, Schollee J, Schymanski EL, Schulze T, Seiler T-B, Tindall AJ, De Aragão Umbuzeiro G, Vrana B, Krauss M (2016) Effect-directed analysis supporting monitoring of aquatic environments - an in-depth overview. Sci Total Environ 544:1073-1118

10. Brack W, Schmitt-Jansen M, Machala M, Brix R, Barceló D, Schymanski E, Streck G, Schulze T (2008) How to confirm identified toxicants in effectdirected analysis. Anal Bioanal Chem 390:1959-1973

11. Brack W, Dulio V, Agerstrand M, Allan I, Altenburger R, Brinkmann M, Bunke D, Burgess RM, Cousins I, Escher BI, Hernandez FJ, Hewitt LM, Hilscherova K, Hollender J, Hollert H, Kase R, Klauer B, Lindim C, Herraez DL, Miege C, Munthe J, O'Toole S, Posthuma L, Rudel H, Schafer RB, Sengl $M$, Smedes F, van de Meent $D$, van den Brink PJ, van Gils J, van Wezel AP, Vethaak AD, Vermeirssen E, von der Ohe PC, Vrana B (2017) Towards the review of the European Union Water Framework Directive: recommendations for more efficient assessment and management of chemical contamination in European surface water resources. Sci Total Environ 576:720-737

12. Brack W, Escher BI, Müller E, Schmitt-Jansen M, Schulze T, Slobodnik J, Hollert H (2018) Towards a holistic and solution-oriented monitoring of chemical status of European water bodies: how to support the EU strategy for a non-toxic environment? Environ Sci Eur 30(1):33

13. Brack W, Ait Aissa S, Backhaus T, Dulio V, Escher BI, Faust M, Hilscherova K, Hollender J, Hollert H, Müller C, Munthe J, Posthuma L, Seiler T-B, Slobodnik J, Teodorovic I, Tindall AJ, de Aragão Umbuzeiro G, Zhang X, Altenburger R (2019) Effect-based methods are key. The European Collaborative Project SOLUTIONS recommends integrating effect-based methods for diagnosis and monitoring of water quality. Environ Sci Eur. https://doi.org/10.1186/s12302-019-0192-2

14. Burdon FJ, Munz NA, Reyes M, Focks A, Joss A, Räsänen K, Altermatt F, Eggen R, Stamm C (2019) Agriculture versus wastewater pollution as drivers of macroinvertebrate community structure in streams submitted. Sci Total Environ 659:1256-1265

15. Busch W, Schmidt S, Kühne R, Schulze T, Krauss M, Altenburger R (2016) Micropollutants in European rivers: a mode of action survey to support the development of effect-based tools for water monitoring. Environ Toxicol Chem 35:1887-1898

16. Chapman PM, Hollert H (2006) Should the sediment quality triad become a tetrad, a pentad, or possibly even a hexad? J Soils Sediments 6(1):4-8

17. Deutschmann B, Kolarevic S, BrackW, Kaisarevic S, Kostic J, KracunKolarevic M, Liska I, Paunovic M, Seiler TB, Shao Y, Sipos S, Slobodnik J, Teodorovic I, Vukovic-Gacic B, Hollert H (2016) Longitudinal profiles of the genotoxic potential of the River Danube on erythrocytes of wild fish assessed using the comet and micronucleus assay. Sci Total Environ 573:1441-1449

18. Di Paolo C, Ottermanns R, Keiter S, Ait-Aissa S, Bluhm K, Brack W, Breitholtz M, Buchinger S, Carere M, Chalon C, Cousin X, Dulio V, Escher Bl, Hamers T, Hilscherova K, Jarque S, Jonas A, Maillot-Marechal E, Marneffe Y, Nguyen MT, Pandard P, Schifferli A, Schulze T, Seidensticker S, Seiler TB, Tang J, van der Oost R, Vermeirssen E, Zounkova R, Zwart N, Hollert H (2016) Bioassay battery interlaboratory investigation of emerging contaminants in spiked water extracts - towards the implementation of bioanalytical monitoring tools in water quality assessment and monitoring. Water Res 104:473-484

19. Dulio V, van Bavel B, Brorstrom-Lunden E, Harmsen J, Hollender J, Schlabach M, Slobodnik J, Thomas K, Koschorreck J (2018) Emerging pollutants in the EU: 10 years of NORMAN in support of environmental policies and regulations. Environ Sci Eur 30(1):5

20. EEA (European Environment Agency) (2012) European waters-assessment of status and pressures. https://www.eea.europa.eu/publications/ european-waters-assessment-2012. Accessed 24 Oct 2018

21. EEA (European Environment Agency) (2013) Assessment of cost recovery through water pricing. https://www.eea.europa.eu/publications/asses sment-of-full-cost-recovery. Accessed 8 Nov 2018

22. EEA (European Environment Agency) (2018) European waters. Assessment of status and pressures 2018. https://www.eea.europa.eu/publi cations/state-of-water. Accessed 24 Oct 2018

23. EEA (European Environment Agency) (2019) Chemicals in Europe's surface waters. https://www.eea.europa.eu/publications/chemicals-in-europ ean-waters. Accessed 24 Jan 2019

24. Eide I, Neverdal G, Thorvaldsen B, Arneberg R, Grung BR, Kvalheim OM (2004) Toxicological evaluation of complex mixtures: fingerprinting and multivariate analysis. Environ Toxicol Pharmacol 18(2):127-133

25. Escher B, Leusch F (2012) Bioanalytical tools in water quality assessment. IWA Publishing, London

26. Escher BI, van Daele C, Dutt M, Tang JYM, Altenburger R (2013) Most oxidative stress response in water samples comes from unknown chemicals: the need for effect-based water quality trigger values. Environ Sci Technol 47(13):7002-7011

27. Escher BI, Allinson M, Altenburger R, Bain PA, Balaguer P, Busch W, Crago J, Denslow ND, Dopp E, Hilscherova K, Humpage AR, Kumar A, Grimaldi M, Jayasinghe BS, Jarosova B, Jia A, Makarov S, Maruya KA, Medvedev A, Mehinto AC, Mendez JE, Poulsen A, Prochazka E, Richard J, Schifferli A, Schlenk D, Scholz S, Shiraishi F, Snyder S, Su G, Tang JYM, Burg BVD, Linden SCVD, Werner I, Westerheide SD, Wong CKC, Yang M, Yeung BHY, Zhang X, Leusch FDL (2014) Benchmarking organic micropollutants in wastewater, recycled water and drinking water with in vitro bioassays. Environ Sci Technol 48(3):1940-1956

28. Escher BI, Ait-Aissa S, Behnisch PA, BrackW, Brion F, Brouwer A, Buchinger S, Crawford S, Hamers THM, Hettwer K, Hilscherova K, Hollert H, Kase R, Kienle C, Legradi J, Tuerk J, van der Oost R, Vermeirssen E, Neale PA (2018) Effect-based trigger values for in vitro and in vivo bioassays performed on surface water extracts supporting the environmental quality standards (EQS) of the European Water Framework Directive. Sci Total Environ 628-629:748-765

29. EU (European Commission) (2000) Directive 2000/60/EC of the European Parliament and of the Council of 23 October 2000 establishing a framework for Community action in the field of water policy. In Official Journal of the European Communities

30. EU-CIS (European Union- Common Implementation Strategy) (2011) Technical guidance for deriving environmental quality standards. Guidance document No. 27. https://circabc.europa.eu/sd/a/0cc3581 b-5f654b6f-91c6-433a1e947838/TGD-EQS\%20CIS-WFD\%2027\%20EC\%20201 1.pdf

31. Federal Water Act (2000) Federal Law Gazette I

32. German Waste Water Ordinance (2009) Federal Law Gazette I, pp 4047-4050

33. Hashmi MAK, Escher BI, Krauss M, Teodorovic I, Brack W (2018) Effectdirected analysis (EDA) of Danube River water sample receiving untreated municipal wastewater from Novi Sad, Serbia. Sci Total Environ 624:1072-1081

34. Hollender J, Schymanski EL, Singer HP, Ferguson PL (2017) Nontarget screening with high resolution mass spectrometry in the environment: ready to go? Environ Sci Technol 51:11505-11512 
35. Hug C, Sievers M, Ottermanns R, Hollert H, Brack W, Krauss M (2015) Linking mutagenic activity to micropollutant concentrations in wastewater samples by partial least square regression and subsequent identification of variables. Chemosphere 138:176-182

36. Hug C, Ulrich N, Schulze T, Brack W, Krauss M (2014) Identification of novel micropollutants in wastewater by a combination of suspect and nontarget screening. Environ Pollut 184:25-32

37. Könemann S, Kase R, Simon E, Swart K, Buchinger S, Schlüsener M, Hollert H, Escher BI, Werner I, Aitt-Aïssa S, Vermeirssen E, Dulio V, Valsecchi S, Polesello S, Behnisch P, Javurkova B, Perceval O, Di Paolo C, Olbrich D, Sychrova E, Schlichting R, Leborgne L, Clara M, Scheffknecht C, Marneffe Y, Chalon C, Tušil P, Soldàn P, von Danwitz B, Schwaiger J, Becares San Martín, Bersani F, Hilscherová K, Reifferscheid G, Ternes T, Carere M (2018) Effect-based and chemical analytical methods to monitor estrogens under the European Water Framework Directive. TrAC Trends Anal Chem 102:225-235

38. König M, Escher BI, Neale PA, Krauss M, Hilscherová K, Novák J, Teodorović I, Schulze T, Seidensticker S, Kamal Hashmi MA, Ahlheim J, Brack W (2017) Impact of untreated wastewater on a major European river evaluated with a combination of in vitro bioassays and chemical analysis. Environ Pollut 220:1220-1230

39. Küster E, Dorusch F, Vogt C, Weiß H, Altenburger R (2004) On line biomonitors used as a tool for toxicity reduction evaluation of in situ groundwater remediation techniques. Biosens Bioelectron 19(12):1711-1722

40. Kuzmanovic M, Ginebreda A, Petrovic M, Barceló D (2015) Risk assessment based prioritization of 200 organic micropollutants in 4 Iberian rivers. Sci Total Environ 503-4:289-299

41. Malaj E, von der Ohe PC, Grote M, Kühne R, Mondy CP, Usseglio-Polatera P, Brack W, Schäfer RB (2014) Organic chemicals jeopardise freshwater ecosystems health on the continental scale. Proc Natl Acad Sci 111(26):9549-9554

42. Moschet C, Wittmer I, Simovic J, Junghans M, Piazzoli A, Singer H, Stamm C, Leu C, Hollender J (2014) How a complete pesticide screening changes the assessment of surface water quality. Environ Sci Technol 48:5423-5432

43. Muschket M, Di Paolo C, Tindall AJ, Touak G, Phan A, Krauss M, Kirchner K, Seiler T-B, Hollert H, BrackW (2018) Identification of unknown antiandrogenic compounds in surface waters by effect-directed analysis (EDA) using a parallel fractionation approach. Environ Sci Technol 52(1):288-297

44. Muz M, Ost N, Kühne R, Schüürmann G, Brack W, Krauss M (2017) Nontargeted detection and identification of (aromatic) amines in environmental samples based on diagnostic derivatization and LC-high resolution mass spectrometry. Chemosphere 166:300-310

45. Muz M, Dann JP, Jäger F, Brack W, Krauss M (2017) Identification of mutagenic aromatic amines in river samples with industrial wastewater impact. Environ Sci Technol 51(8):4681-4688

46. Muz M, Krauss M, Kutsarova S, Schulze T, BrackW (2017) Mutagenicity in surface waters: synergistic effects of carboline alkaloids and aromatic amines. Environ Sci Technol 51(3):1830-1839

47. Neale PA, Ait-Aissa S, BrackW, Creusot N, Denison MS, Deutschmann BR, Hilscherová K, Hollert H, Krauss M, Novak J (2015) Linking in vitro effects and detected organic micropollutants in surface water using mixturetoxicity modeling. Environ Sci Technol 49(24):14614-14624

48. Neale PA, Altenburger R, Ait-Aissa S, Brion F, Busch W, de Aragão Umbuzeiro G, Denison MS, Du Pasquier D, Hilscherova K, Hollert H, Morales DA, Novac J, Schlichting R, Seiler T-B, Serra H, Shao Y, Tindall AJ, Tollefsen KE, Williams TD, Escher BI (2017) Development of a bioanalytical test battery for water quality monitoring: fingerprinting identified micropollutants and their contribution to effects in surface water. Water Res 123:734-750

49. Neale PA, Munz NA, Ait-Aissa S, Altenburger R, Brion F, Busch W, Escher Bl, Hilscherova K, Kienle C, Novak J, Seiler T-B, Shao Y, Stamm C, Hollender $J$ (2017) Integrating chemical analysis and bioanalysis to evaluate the contribution of wastewater effluent on the micropollutant burden in small streams. Sci Total Environ 576:785-795

50. Neale PA, Brack W, Ait-Aissa S, Busch W, Hollender J, Krauss M, MaillotMaréchal E, Munz NA, Schlichting R, Schulze T, Vogler B, Escher B (2018) Solid-phase extraction as sample preparation of water samples for cell-based and other in vitro bioassays. Environ Sci Process Impacts 20:493-504
51. Neale PA, Brack W, Ait-Aissa S, Busch W, Hollender J, Krauss M, MaillotMaréchal E, Munz NA, Schlichting R, Schulze T, Vogler B, Escher BI (2018) Solid-phase extraction as sample preparation of water samples for cellbased and other in vitro bioassays. Environ Sci Process Imp 20:493-504

52. Novák J, Vrana B, Rusina T, Okonski K, Grabic R, Neale PA, Escher BI, Macová M, Ait-Aissa SS, Creusot N, Allan I, Hilscherová K, Macova M, AitAissa SS, Creusot N, Allan I, Hischerova K (2018) Effect-based monitoring of the Danube River using mobile passive sampling. Sci Total Environ 636:1608-1619

53. Phia H, Dulio V, Hanke G (2010) Workshop report river basin-specific pollutants. Identification and Monitoring, EU, Ispra. ISBN 978-92-79-18471-0

54. Reichenberg F, Mayer P (2006) Two complementary sides of bioavailability: accessibility and chemical activity of organic contaminants in sediments and soils. Environ Toxicol Chem 25:1239-1245

55. Reineke N, Bester K, Huhnerfuss H, Jastorff B, Weigel S (2002) Bioassaydirected chemical analysis of River Elbe surface water including large volume extractions and high performance fractionation. Chemosphere 47:717-723

56. Rico A, Van den Brink PJ, Leitner P, Graf W, Focks A (2016) Relative influence of chemical and non-chemical stressors on invertebrate communities: a case study in the Danube River. Sci Total Environ 571:1370-1382

57. Sabater S, Barceló D, De Castro-Catalá N, Ginebreda A, Kuzmanovic M, Petrovic M, Picó Y, Ponsatí L, Torné B, Muñoz I (2016) Shared effects of organic microcontaminants and environmental stressors on biofilms and invertebrates in impaired rivers. Environ Pollut 210:303-314

58. Schmidt S, Busch W, Altenburger R (2017) Biotestverfahren zur Abschätzung von Wirkpotenzialen in der aquatischen Umwelt: Vorschlag einer modularen Biotestbatterie für das aquatische Umweltmonitoring als Ergebnis einer systematischen Literaturrecherche und Bewertung. LUBW Landesanstalt für Umwelt Baden-Württemberg, Karlsruhe

59. Schollée JE, Bourgin M, von Gunten U, McArdell CS, Hollender J (2018) Characterizing non-target peaks across a wastewater treatment train including ozonation and post-treatment. Water Res 142:267-278

60. Schulze T, Ahel M, Ahlheim J, Ait-Aissa S, Brion F, Di Paolo C, Froment J, Hidasi AO, Hollender J, Hollert H, Hu M, Klolss A, Koprivica S, Krauss M, Muz M, Oswald P, Petre M, Schollee JE, Seiler TB, Shao Y, Slobodnik J, Sonavane M, Suter MJF, Tollefsen KE, Tousova Z, Walz KH, Brack W (2017) Assessment of a novel device for onsite integrative large-volume solid phase extraction of water samples to enable a comprehensive chemical and effect-based analysis. Sci Total Environ 581:350-358

61. Shao Y, Hollert H, Tarcai Z, Deutschmann B, Seiler T-B (2019) Integrating bioassays, chemical analysis and in silico techniques to identify genotoxicants in surface water. Sci Total Environ 650:3084-3092

62. Tang JYM, Busetti F, Charrois JWA, Escher BI (2014) Which chemicals drive biological effects in wastewater and recycled water? Water Res 60:289-299

63. Ternes TA, Giger W, Joss A (2006) Introduction. Human pharmaceuticals, hormones and fragrances. The challenge of micropollutants in urban water management. IWA Publishing, London, pp 1-13

64. Toušová Z, Oswald P, Slobodnik J, Blaha L, Muz M, Hu M, Brack W, Krauss M, Di Paolo C, Tarcai Z, Seiler TB, Hollert H, Koprivica S, Ahel M, Schollee JE, Hollender J, Suter MJ, Hidasi AO, Schirmer K, Sonavane M, Ait-Aissa S, Creusot N, Brion F, Froment J, Almeida AC, Thomas K, Tollefsen KE, Tufi S, Ouyang X, Leonards P, Lamoree M, Torrens VO, Kolkman A, Schriks M, Spirhanzlova P, Tindall A, Schulze T (2017) European demonstration program on the effect-based and chemical identification and monitoring of organic pollutants in European surface waters. Sci Total Environ 601-602:1849-1868

65. Toušová Z, Vrana B, Smutná M, Novák J, Klučárová V, Grabic R, Slobodník J, Giesy JP, Hilscherová K (2019) Analytical and bioanalytical assessments of organic micropollutants in the Bosna River using a combination of passive sampling, bioassays and multi-residue analysis. Sci Total Environ 650:1599-1612

66. Van den Brink P, Baird DJ, Baveco HJM, Focks A (2013) The use of traitsbased approaches and ecooxicological modelst o advance the ecological risk assessment framework for chemicals. Int Environ Assess Manag 9:e47-e57

67. von der Ohe PC, Dulio V, Slobodnik J, De Deckere E, Kuehne R, Ebert RU, Ginebreda A, De Cooman W, Schuurmann G, Brack W (2011) A new risk assessment approach for the prioritization of 500 classical and emerging organic microcontaminants as potential river basin specific pollutants 
under the European Water Framework Directive Sci Tot Environ 409:2064-2077

68. Vrana B, Smedes F, Allan I, Rusina T, Okonski K, Hilscherová K, Novák J, Tarábek P, Slobodník J (2018) Dynamic mobile passive sampling of trace organic compounds: evaluation of sampler performance in the Danube river. Sci Total Environ 636:1597-1607

69. Vrana B, Smedes F, Hilscherova K (2019) Passive sampling of waterborne contaminants. In: Seiler T-B, Brinkmann M (eds) In situ bioavailability and toxicity of organic chemicals in aquatic systems. Methods in pharmacology and toxicology. Springer, New York (in Press)

70. Wernersson A-S, Carere M, Maggi C, Tusil P, Soldan P, James A, Sanchez W, Dulio V, Broeg K, Reifferscheid G, Buchinger S, Maas H, Van Der Grinten E, O’Toole S, Ausili A, Manfra L, Marziali L, Polesello S, Lacchetti I, Mancini
L, Lilja K, Linderoth M, Lundeberg T, Fjallborg B, Porsbring T, Larsson DGJ, Bengtsson-Palme J, Forlin L, Kienle C, Kunz P, Vermeirssen E, Werner I, Robinson CD, Lyons B, Katsiadaki I, Whalley C, den Haan K, Messiaen M, Clayton H, Lettieri T, Carvalho RN, Gawlik BM, Hollert H, Di Paolo C, Brack W, Kammann U, Kase R (2015) The European technical report on aquatic effect-based monitoring tools under the water framework directive. Environ Sci Eur 27:1-11

71. Zonja B, Postigo C, Guillen-Asensio JC, López-García E, Monllor-Alcaraz S, López de Alda M, Brana B, Smedes F, Okonski K, Becanova L, Kraus M, Schymanski E, Neumann S, Zlatarov A, Jager F, Huerta B, Ignatova S, Scrimshaw M (2018) Solutions External Deliverable 10.1 'Guidelines for target and non-target analysis of emerging contaminants in water and biota'. https://www.solutions-project.eu/project/. Accessed 1 Feb 2019

\section{Submit your manuscript to a SpringerOpen ${ }^{\circ}$ journal and benefit from:}

- Convenient online submission

- Rigorous peer review

- Open access: articles freely available online

- High visibility within the field

- Retaining the copyright to your article

Submit your next manuscript at $\boldsymbol{\nabla}$ springeropen.com 